\title{
Malaysian Scenario on Access and Facilities for Persons with Disabilities: A literature review
}

\author{
H. Kamarudin ${ }^{1}$, N. R. Muhamad Ariff ${ }^{2}$, W. Z. Wan Ismail ${ }^{3}$, A.F. Bakri ${ }^{4}$, Z. Ithnin ${ }^{5}$ \\ 1,2,3,4,5 Faculty of Architecture, Planning and Surveying, Universiti Teknologi MARA, 40450 Shah \\ Alam, Selangor, Malaysia
}

\begin{abstract}
Physical barriers may hamper persons with disabilities (PWDs) movement in built environment. The needs of physical barrier- free environment are internationally acknowledged. This study explores the Malaysian scenario on access and facilities for PWDs by reviewing relevant legislation and guidelines, and literatures that examined the access and facilities provided in public buildings. This study identifies that Malaysia has plays its roles by establishing the relevant acts and legislation on PWDs needs and requirements. Nevertheless, previous studies on PWDs in Malaysia, demonstrated that there are still lacking on the implementation of the practice towards the acts and legislations. This study suggests that the application of the acts and legislation should be comprehensive covering all types of public buildings in Malaysia. In addition, enforcement by the local authorities and government agencies is crucial in order to successfully creating a barrier-free environment for all.
\end{abstract}

\section{Introduction}

In Malaysia, the Persons with Disabilities Act 2008 (Act 685) (PWDA) define persons with disabilities (PWDs) as "persons with physical, mental and intellectual disabilities that hindered them from fully participating in a normal way in the community way of life." As the PWDs has the rights to access and use public facilities, amenities, services and buildings as described in the PWDA, removing barriers and providing access are a fundamental needs. However, Yusof [1] realizes that the consideration of equal accessibility to outdoor environments in Malaysia is still lacking.

The increase in population of the PWDs in Malaysia has resulted demand for the provision of access and facilities in and outside the building, especially in government institutions [2]. Compared to the persons without disabilities, the PWDs have less opportunity to attend activities because of the inaccessible environment. The inaccessible environment will lead to a stress, low self-esteem and discomfiture to the PWDs when they are in public that affects them negatively [3]. Therefore, appropriate considerations shall be taken by the appropriate governing bodies to ensure access and facilities are conforming to the legislation, statutory and guidelines provided for the PWDs. However, the implementation of these practices are always not fulfilling to the PWDs needs as Malaysia has still lack in provision of user-friendly built environment as stated in the legislation, statutory and guidelines [4]. 


\section{Related legislation, statutory and guidelines}

The Person with Disabilities Act (Act 685) (PWDA) which was introduced in Malaysia in 2008 has evolves the perspective of PWDs access and facilities from charity and welfare, based on the Medical Model, to a recognition of the Social Model [5]. PWDs should not be seen out of sympathy while they should enjoy the existing facilities as other legal citizens [6]. The main aim for the PWDA is to provide an equalization rights to all society. However, it is noted that Malaysia has limitations in enforcing legislation pertaining to access and facilities for PWDs [5]. Roulstone and Prideaux [7] agreed that although legislative coherently provided for the PWDs, however there is still lack of enforcement towards what is provided. Other related acts on the access and facilities for PWDs in Malaysia are the Town and Country Planning Act 1976 (Act 172) and Street, Drainage and Building Act, 1974 (Act 133). The Act 172 is translated as the planning permission requirements while Act 133 is detailed out in the Uniform Building By-Laws as the building plan approval requirements.

UBBL is a by-law under the Street, Drainage and Building Act, 1974 (Act 133).Amendments has been made which resulted the insertion of the UBBL 34A which requires buildings to comply with the Malaysian Standard Code of Practice on Access for Disabled Person (MS). All new buildings are compulsory to have access to enable PWDs to get into, out of and within the buildings, otherwise, fines will be given under the provisions of the Street, Drainage and Building Act 1974 [8]. Existing buildings have to comply with the requirements within three years since the by-law came into force. However, Hussein and Yaacob [5] claimed that the implementation, compliance and enforcement of the access and facilities for PWDs are lax.

The MS is a decisive instrument providing guidelines in designing the accessible facilities for the PWDs [9]. They are categorized into three consecutive groups namely; MS 1184:2002 Code of Practice on Access for Disabled Persons to Public Buildings (First Revision), MS 1183:1990 Code of Practice for Means of Escape for Disabled Persons and MS 1331: 2003 Code of Practice for Access of Disabled Persons outside Buildings. The MS needs emphasized on the wheelchair users (any kind of chair, whether accompanied or not), crutch users (including in practice arm amputers), blind people (including those with low vision) and deaf people (including the hard hearing) [9].

The compliance to MS 1331:2003 is not required in the UBBL. Fortunately, according to [4] the requirement to fulfil the MS 1331: 2003 are written in the Development Order (for granting Planning Permission) as "facilities for the PWDs must be allocate to comply the MS1183:1990, MS1184:2002 and MS1131:2003. The facilities need to be indicated in the submitted plans before it can be approved." However, Hussein and Yaacob [5] reveal that a revision exercise commenced in 2010 to merge MS 1184:2002 and MS 1331:2003 into one new standard will be available in 2013. The descriptions of the Malaysian Standards are as shown in Table 1.

Table 1: Malaysian Standard Code of Practice on Access for Disabled Persons

\begin{tabular}{|c|c|}
\hline Malaysian Standards & Description \\
\hline $\begin{array}{l}\text { Malaysian Standard 1184:2002, } \\
\text { Code of Practice on Access for } \\
\text { Disabled Persons to Public } \\
\text { Buildings (First Revision) }\end{array}$ & $\begin{array}{l}\text { It specifies the basic requirements of buildings and related facilities in } \\
\text { order to permit access for PWDs. }\end{array}$ \\
\hline $\begin{array}{l}\text { Malaysian Standard 1183:1990 } \\
\text { Code of Practice for Means of } \\
\text { Escape for Disabled Persons }\end{array}$ & $\begin{array}{l}\text { The practices use as guidance for a new building construction work and } \\
\text { modification. It is to provide the planning, action and requirement that } \\
\text { should be applied on building in aspect of fire safety for PWDs. The } \\
\text { provisions are including of fire escape, staircase and others. }\end{array}$ \\
\hline $\begin{array}{l}\text { Malaysian Standard 1331:2003, } \\
\text { Code of Practice for Access of } \\
\text { Disabled Persons Outside } \\
\text { Buildings (First Revision) }\end{array}$ & $\begin{array}{l}\text { It specifies the basic requirements for the provision and design of outdoor } \\
\text { facilities so that they are accessible and usable by PWDs. This standard } \\
\text { supersedes MS 1331:1993. This MS is not included in the Uniform } \\
\text { Building (Amendment) By-Laws (UBBL) 1991. However the } \\
\text { requirement to conform to this code is included for getting planning } \\
\text { permission which is stated in the Development Order (DO) requirement. }\end{array}$ \\
\hline
\end{tabular}


The adaptation of UD in Malaysia is to in line with other developed countries in providing efficient access and facilities for all users. UD is designed for the usage of all without any special design for a certain group of people which promote a design that does not discriminate people based on different abilities. The key principles of UD are shown as in Table 2.

Table 2: The Key Principles of Universal Design

\begin{tabular}{ll}
\hline Principle & Description \\
\hline Equitable Use & The design is useful and marketable to people with diverse abilities \\
Flexibility in Use & $\begin{array}{l}\text { The design accommodates a wide range of individual preferences and } \\
\text { abilities }\end{array}$ \\
Simple and Intuitive Use & $\begin{array}{l}\text { Use of the design is easy to understand, regardless of the user's experience, } \\
\text { knowledge, language skills, or current concentration level }\end{array}$ \\
Perceptible Information & $\begin{array}{l}\text { The design communicates necessary information effectively to the user, } \\
\text { regardless of ambient conditions or the user's sensory abilities }\end{array}$ \\
Tolerance for Error & $\begin{array}{l}\text { The design minimizes hazards and the adverse consequences of accident or } \\
\text { unintended actions. }\end{array}$ \\
Low Physical Effort & $\begin{array}{l}\text { The design can be used efficiently and comfortably and with a minimum of } \\
\text { fatigue. }\end{array}$ \\
Size and Space for Approach & $\begin{array}{l}\text { Appropriate size and space is provided for approach, reach, manipulation and } \\
\text { use regardless of user's body size, posture or mobility. }\end{array}$
\end{tabular}

Rahim and Abdullah [10] aware that in many developing countries, the awareness and inclusion of universal design is still in its initial stage where the cities' authorities have not fully enforced the requirement of providing access to PWDs in the built environment, including Malaysia. However, Kadir et. al. [11] highlight that there is a positive development in terms of public awareness on access and facilities for PWDs in Malaysia even though the accurate understanding of UD theory is still low among Malaysian society. Some people have misunderstood that UD is exclusively caters the needs of PWDs access and facilities in the built environment.

There is a few other design terms related to the provision of access and facilities for PWDs. Bringolf [12] concludes the term 'universal design', 'design for all' and 'inclusive design' as "designing for the whole of the population bell curve by creating the maximum utility for the maximum number of people regardless of age, culture, and education or ability level."

'Accessible design' concerns mainly with PWDs on accessibility and promote UD which is regarded to be more embracing of all types of people's needs, including the elderly, children and pregnant women [5] and 'barrier-free environment' targets for retrofitting of buildings or facilities to accommodate physically impaired person [13].

\section{Access audit}

As a rapid developing country, Malaysia offers technologically advanced services and facilities. However not all of the people are able to conduct their activities because of the lack of physical access for the PWDs [8]. According to Maidin [14] PWDs still have problem to access facilities such as education, employment, enjoying social life, business premises, work places, public transport and public facilities. Although, if there are access and facilities provided, it is mainly for those who are using wheelchairs but does not include for those who suffered from visual, hearing or intellectual 
disabilities [15]. Among the problems that faced by the PWDs are difficulty in going up steep ramps and lack of guiding blocks for the vision impaired.

Malaysia has set legislation, statutory and guidelines in providing access and facilities for PWDs such as UBBL, MS, UD and PWDA. However, there is still lack of compliance made by the building owners. With regards to the problem, access audit should be conducted widely for existing buildings and other built environment in order to ensure the compliance of those requirements set especially as in the MS [4].

Holmes-Siedle [16] suggests that the 'usability' of the building for disabled people can be examined by conducting an access audit towards an existing building against predetermined criteria. Main purpose of access audit is to identify barriers that need to be rectified so that the public facilities can be use by everyone equally. In conducting the access audit, one can examine how well the facilities provided at the existing building used by any of the PWDs independently [16].

Currently in Malaysia, the access audit consultants offer special training on access audit especially to the local authority technical staff. The participants are highlighted to the needs of access and facilities in the built environment. Simulation exposing the participants on how being on a wheelchair and walking with a stick, and together assisting the PWDs in the built environment for the access audit training are really useful for the participants to get a better understanding [17]. The participants are expected to conduct the real access audit successfully where then they can give recommendations on how to upgrade the current access and facilities provided.

\section{Access and facilities for PWDs in public buildings}

The implementation of the MS as described in the MS 1184:2002 are applicable to all buildings that PWDs may use as a general public, visitors or for the purpose of employment, excluding residential buildings. Even though the access and facilities for PWDs are improving, however, literatures highlight on the issues of physical barriers in public buildings are still common.

\subsection{Public transportation terminal}

Soltani et. al. [18] stated that the access and facilities in public transportation terminal is designed inefficiently that leads to a limited space for the PWDs to move about. The government bodies in Malaysia should put some more effort for some improvements and re-designing of the existing facilities for equality so that the PWDs would not feel left out. Actions has been taken by the transportation industry to upgrade the implementation of universal design facilities i.e. in the Malaysian Railways (KTMB) and the Mass Transit Train (LRT). In the meantime, the Ministry of Transportation is coming out for guidelines for accessible buses while Malaysian Airlines is providing wheelchair services assistance with free of charge accommodation.

\subsection{Commercial Complex}

Commercial complex is said to be the busiest public place and takes up different kinds of activities. Nowadays, Malaysia has increased the accessibility and facilities provided for PWDs that lead to an acceptable satisfaction such as the introduction ofstair lift as an option for vertical access for the PWDs. However, Hashim et. al. [19] highlighted that there are many physical barriers faced by PWDs in most shopping complexes with the main features that should be considered are the toilet for PWDs, barrier-free access, facilities such as handrails in lifts, car parking for PWDs, clear exit and signage. Inaccessibility found in the case study commercial complex are due to bad design or poor thought out solution, poor planning in accommodating accessible design as part of the budget and lack of enforcement on policies and guidelines [20]. 


\subsection{Buildings of Tourist Attraction}

The heritage and cultural is the main sector of the tourism that can attract both international and domestic visitors at which, in the same time increase the opportunities in employment together with revenue. Yaacob and Hashim [21] suggest that the elderly and PWDs can enjoy visiting heritage sites as long as the principle of the barrier-free of 'accessibility, safety and usability' is implemented. The main cause that disables the PWDs to participate is due to lack of access and facilities provided. Additional features on having access and facilities for PWDs shall not change the whole view of the heritage building but complimenting with the important activity in conserving the heritage buildings.

\section{PWDs perception on access and facilities for PWDs in Malaysia}

PWDA includes the rights of PWDs at where everyone shall have equal access to public facilities, amenities, services and buildings, and public transport. Khalid [22] reported, according to the President of Barrier-Free Environment and Accessible Transport Group (BEAT), the access and facilities provided in public buildings are improving. Most buildings have ramps and moving walkways that can help PWDs to move about in and within building. However, the ramps and moving walkways mostly provided only at large public buildings. In addition, the non-compliance of the sizes of lifts and toilets also restricted PWDs to freely access and use the facilities provided [22].

Kadir and Jamaludin [23] discover that the visual impaired emphasize on the design of guiding blocks, tactile direction or warning indication to facilities in the building, and signage of the building. The hearing impaired focus on the attitude of front-liner staff and signage while the wheelchair-bound emphasize on high gradients or level changes, ramp, barriers in front of ablution faucets, and size of the door and furniture layout in PWDs restroom. According to their findings, Kadir and Jamaludin [23] notice that policies have been given extra attention to guidelines or design for the wheelchairbound user, while other PWDs like the hearing impaired were neglected.

\section{Conclusion}

This study explores Malaysian scenario on access and facilities for PWDs by discussing the relevant legislation and guidelines established by the Malaysian Government, and examined previous studies that have investigated the built-environment of public buildings. As 'Building an Environment that Enhances Quality of Life' is one of the five Strategic Thrust of the Tenth Malaysian Plan (20112015) announced by the Prime Minister of Malaysia, Dato' Sri Mohd Najib, it indicates that the needs of physical access and facilities in the built environment are vital for PWDs. The physical access and facilities requires continuous improvement as the life in future is more challenging. Furthermore, PWDs are not left out in contributing to economic, social and development stability of a country.

As for Malaysia, the UBBL and MS are the main references that required to be implemented in any public buildings development in Malaysia. MS provide guidance on the basic requirements on access and facilities that are accessible and usable by PWDs for a new and modification building constructions, including of fire safety provision.

Previous studies recognized that the lack of awareness of the UD concept has resulted in the provision of physical access and facilities for PWDs are not entirely to their benefit. Studies by Malaysian researchers revealed that public buildings in Malaysia are partially complying with the UBBL and MS. However there are cases that facilities and access provided are not accessible and reachable by PWDs.

A solution to these problems should be highlighted by the policy makers and enforcement bodies. An access audit particularly the simulation is crucial to be compulsory implemented by the third party in any public building in order to make sure the effectiveness of the access and facilities provided. This exercise should also covers to the modified constructions such as refurbishment and renovation works, and conservation works for heritage buildings. Future research should emphasis on the needs 
of access audit and continuously investigates the continuous improvement actions, not only on the legislation but also on the aspects of universal designs.

\section{Acknowledgement}

We would like to thank the Dean of the Faculty of Architecture, Planning and Surveying, Universiti Teknologi MARA for giving the opportunity to participate in this conference. Research Management Institute owned special thanks by the authors for funding the research.

\section{References}

1. Yusof, L.M. (2010). Accessibility for wheelchair users in publicparks: A comparison between Adelaide and Kuantan.Retrieved on August 19, 2013 from http://umpir.ump.edu.my

2. Sanmargaraja, S. and Seow Ta Wee (2011). Kajian penyediaan fasiliti orang kurang upaya di institusi kerajaan di Nusajaya, Jahor Bahru. Retrieved on March 1, 2012 from http://eprints.uthm.edu.my

3. Iwasaki, Y. and Mactavish, J.B. (2005). Ubiquitous yet unique: Perspective of people with disabilities on stress. Rehabilitation Counseling Bulletin, 48(4). 194-208.

4. Kamarudin, H. (2007). The implementation of the SIRIM Codes of Practice for Disabled Persons by DBKL. Unpublished dissertation. Universiti Teknologi MARA, Shah Alam.

5. Hussein, H. and Yaacob, N.M. (2012). Development of accessible design in Malaysia. Procedia Social and Behavioral Sciences 68 (2012), 121-133.

6. Tiun and Khoo (2013). Challenges faced by Malaysian with disabilities in the world of employment. Universiti Sains Malaysia, Penang. Retrieved on October 1, 2013 from http://dcidj.org

7. Roulstone, A. and Prideaux, S. (2009). Constructing reasonables: Environmental access policy for disabled wheelchair users in four European Union Countries. ALTER, European Journal of Disability Research 3, 360-377.

8. Kamarudin, H., Hashim, A. E., Mahmood, M., Ariff, N. R. M., and Ismail, W. Z. W. (2012). The implementation of the Malaysian Standard Code of Practice on Access for Disabled Persons by local authority. Procedia - Social and Behavioral Sciences, 50 (2012), 442-451.

9. Kadir, S.A. and Jamaludin, M. (2012). Applicability of Malaysian Standards and Universal Design in public building in Putrajaya. Procedia - Social and Behavioral Sciences 36 (2012), 659 -669 .

10. Rahim, A.A. and Abdullah, F. (2009). Access audit on universal design: The case of Kota Kinabalu Water Front. The International Journal of Interdisciplinary Social Sciences Volume 4.

11. Kadir, S.A., Jamaludin, M. and Rahim, A.A (2009). Building managers' views on accessibility and UD implementation in public buildings: Putrajaya. Journal of Asian Behavioural Studies, 3(8).

12. Bringolf, J. (2008). Universal design: is it accessible? Multi, 1 (2), 45-52.

13. Audirac, I. (2008). Assessing transit as universal design. Journal of Planning Literature, 4-16.

14. Maidin, A.J. (2012). Legal framework regulating for improving accessibility to built environment for disabled persons in Malaysia. Retrieved on October 1, 2013 from http://irep.iium.edu.my

15. Japan International Cooperation Agency (JICA) (2009), Barrier-free planning in Malaysiacollection of information and verification. Retrieved on September 30, 2013 from http://www.jobcoachmalaysia.com

16. Holmes-Siedle, J. (1996). Barrie-free design. A manual for building designers and managers. Architectural Press. 
17. Kamarudin, H., Ariff, N.R.M., Ismail, W.Z.W and Ismail, E.D. (2013). Auditing Malaysian Standard compliance for access and facilities for persons with disabilities in local authority buildings and its surrounding. $3^{\text {rd }}$ International Conference on Universal Design in the Built Environment 2013, Putrajaya.

18. Soltani, S. H. K., Sham, M., Awang, M., \& Yaman, R. (2012). Accessibility for disabled in public transportation terminal. Procedia - Social and Behavioral Sciences, 35(2012), 89-96.

19. Hashim, A. E., Samikon, S. A., Ismail, F., Kamarudin, H., Jalil, M. N. M., and Arrif, N. M. (2012). Access and accessibility audit in commercial complex: Effectiveness in respect to people with disabilities (PWDs). Procedia Social and Behavioral Sciences, 50 (2012), 452-461.

20. Hashim A. E., Ismail, F., Akida, M., Isnin, Z., Natasha, K., Rahim, M.A. (2011). Disabled facilities in shopping malls: Malaysian perspective.Business \& Management Quarterly Review, 2(4), 56-64.

21. Yaacob, N.M. and Hashim, N.R. (2007). Inclusive heritage tourism: A study on the access needs of disabled and elderly tourists in Malaysia. The $3^{\text {rd }}$ Tourism Outlook Conference and Global Event Congress II, Kuala Lumpur, 227-239.

22. Khalid, K. (2012). User friendly for all.

23. Kadir, S.A. and Jamaludin, M. (2012). Users' satisfaction and perception on accessibility of public buildings in Putrajaya: Access audit study. Procedia - Social and Behavioral Sciences 50 (2012), $429-441$. 